\title{
Mixed-methods Process Evaluation of a Residence-based SARS-CoV-2 Testing Participation Pilot on a UK University Campus during the COVID-19 Pandemic
}

Holly Blake ( $\sim$ holly.blake@nottingham.ac.uk)

University of Nottingham

Sophie Carlisle

University of Nottingham

Lauren Fothergill

University of Nottingham

Juliet Hassard

University of Nottingham

Alex Favier

University of Nottingham

Jessica Corner

University of Nottingham

Jonathan, K Ball

University of Nottingham

Chris Denning

University of Nottingham

\section{Research Article}

Keywords: COVID-19, SARS-CoV-2, Universities, Process evaluation, Public Health, Complex interventions, Mixed-methods, Implementation

Posted Date: December 20th, 2021

DOI: https://doi.org/10.21203/rs.3.rs-1093335/v1

License: (c) This work is licensed under a Creative Commons Attribution 4.0 International License. Read Full License 


\section{Abstract}

Background

Regular testing for SARS Coronavirus-2 (SARS-CoV-2) is an important strategy for controlling virus outbreaks on university campuses during the COVID-19 pandemic but testing participation rates can be low. The Residence-Based Testing Participation Pilot (RB-TPP) was a novel intervention implemented at two student residences on a large UK university campus over four weeks. The aim of the pilot was to increase the frequency of asymptomatic SARS-CoV-2 saliva testing onsite. This process evaluation aimed to determine whether RB-TPP was implemented as planned and identify implementation barriers and facilitators.

Methods

A mixed-methods process evaluation was conducted alongside the RB-TPP. Evaluation participants were students (opting in, or out of RB-TPP) and staff with a role in service provision or student support. Monitoring data were collected from the intervention delivery team and meeting records. Data were collected from students via online survey $(n=152)$ and seven focus groups $(n=30)$, and from staff via individual interviews $(n=13)$. Quantitative data were analysed descriptively and qualitative data thematically. Barriers and facilitators to implementation were mapped to the 'Capability, Opportunity, Motivation-Behaviour' (COM-B) behaviour change framework.

\section{Results}

464 students opted to participate in RB-TPP (98\% of students living onsite). RB-TPP was implemented broadly as planned but was terminated early due to concerns relating to national escalation of the COVID-19 Delta variant. Most students (97.9\%) perceived the relaxing of social distancing regulations within residences positively. The majority engaged in asymptomatic testing (88\%); $46 \%$ (52\% of testers) were fully compliant with pre-determined testing frequency. Implementation was facilitated by convenience and efficiency of testing, reduction in the risk of self-isolation and opportunities for students to socialise. Main barriers to implementation were mixed-messages about the rules, ambivalent attitudes, and lack of adherence to COVID-19 protective measures in the minority.

\section{Conclusions}

This process evaluation identifies factors that help or hinder the success of university residence-based outbreak prevention and management strategies. RB-TPP led to increased rates of COVID-19 testing participation among students in university residences. Perceived normalisation of university life significantly enhanced student mental wellbeing. The complexity and challenge generated by multiple lines of communication and rapid adaptions to a changing pandemic context was evident.

Trial registration number

UKAS 307727-02-01; Pre-results. ClinicalTrials.gov Identifier: NCT05045989; post-results (first posted, 16/09/21).

Ethical Approval

FMHS 96-0920

\section{Strengths And Limitations Of This Study}

- This is the first study to report a process evaluation of an initiative aimed to increase student participation in SARSCoV-2 testing in university residences. 
- This study provides a worked example of a pragmatic approach to process evaluation to explore the implementation of a rapid response intervention in the context of a pandemic.

- A strength of the study is that the process evaluation uses both qualitative and quantitative data to illustrate intervention delivery, the facilitators and barriers to implementation and perspectives of multiple participants and stakeholders.

- A limitation of the study is that the process evaluation included only a small number of students who had chosen not to take part in the scheme.

\section{Background}

The coronavirus disease (COVID-19) pandemic caused by the virus SARS-CoV-2, is highly contagious (WHO, 2020) and the majority (>90\%) of the United Kingdom (UK) and world population remain susceptible to infection (India Today, 2020). If not identified and controlled quickly, an outbreak on a university campus would have potential for explosive and extensive spread, threatening the immediate and wider community. National initiatives, such as the UK Track and Trace programme (DHSC, 2020), to target symptomatic cases and their contacts are unlikely to identify university outbreaks rapidly, as published data shows that most infections in these individuals will be asymptomatic (Ebell et al, 2020; Davies et al, 2020). Evidence shows that individuals with minimal or no symptoms can still transmit the virus (Yanes-Lane et al, 2020; Vermund and Pitzer, 2021). Therefore, prevention of largescale virus outbreaks within the University community has required appropriate mitigation (strict personal hygiene, improved estates cleansing etc.) as well as containment (testing, contact tracing and quarantine). High-frequency surveillance testing (i.e., once or twice per week) is considered to be an effective strategy for COVID-19 disease mitigation (Walke, 2020; Barrios et al, 2021).

At the University of Nottingham, asymptomatic testing has been available from an internal Asymptomatic Testing Service (ATS) since September 2020. Students arriving at the University to residences on the campus are offered asymptomatic tests on arrival. A pilot study conducted during the summer of 2020 found high adherence to regular testing and acceptability of socialising via 'household bubbles' (Blake et al, 2020), but this was on the University's rural campus, with the first cohort of students to occupy university residences since the outbreak of the pandemic. By Autumn 2020, the local and national situation had markedly changed (Blake et al, 2021). Students were arriving at, or returning to, campus in a context of a second surge of COVID-19 in the UK, and the highest rates of COVID-19 in a UK higher education setting (Covid-19 Case Dashboard, 2020), with an escalating number of positive cases requiring students to self-isolate (Blake et al, 2021).

Although most students tested on arrival, the majority did not continue with regular (weekly) testing and testing uptake rates rapidly declined (dropping from 58\%-5\%, Blake et al, 2021). This was primarily associated with fear of the negative impacts of self-isolation, loneliness and the impacts of positive test results on peers (Blake et al, 2021). Attempts at enforcing household bubbles and other social distancing rules and regulations that had worked in a different context and environment (Blake et al, 2020) were less acceptable to students living in large traditional residences, on campuses close to the city. While approaches to the delivery of testing in university settings are emerging internationally (e.g., Blake et al, 2020; Packel at al, 2021; Berger Gillam et al, 2021), there is limited evidence on strategies for increase testing uptake. Solutions to increasing rates of testing participation are urgently needed to inform future higher education policy and practice around outbreak prevention and management.

Clustering of positive cases has been identified in university residences (up to 31\%) (Berger Gillam et al, 2021). Recent SARS-CoV-2 transmission modelling suggests that surveillance-based informative testing strategies targeting university residences are more effective at detecting positive cases than random or voluntary testing (Rennert et al, 2021). Therefore, a novel, residence-based enhanced SARS-2 coronavirus testing participation programme (RB-TPP) was initiated, aiming to 
increase the uptake and frequency of SARS-CoV-2 testing in university residences, whilst simultaneously allowing some relaxation of social distancing restrictions within buildings.

Process evaluation is vital for understanding how interventions function in different settings, including if and why they have different outcomes or do not work at all. This is particularly important in trials of complex interventions in 'real world' organisational settings where causality is difficult to determine. We report a process evaluation conducted alongside the RB-TPP that explored the impact and consequences of the programme for students and staff, and established views on key aspects of the programme in order to aid better understanding of how, why and for whom such approaches and interventions are effective. This process evaluation aimed to provide insight into the value of the RB-TPP approach to prevention of COVID-19 outbreaks on university campuses. The objectives were to explore (a) the intervention as it was implemented (to ascertain the degree to which it was implemented as planned); (b) how people participated in and responded to the intervention (to ascertain the barriers and facilitators to implementation); and (c) the contextual characteristics that mediated this relationship and may influence outcomes.

\section{Methods}

\section{Study design}

This is a convergent parallel mixed-methods (Creswell and Clark, 2007) process evaluation following the United Kingdom (UK) Medical Research Council guidelines (Moore et al, 2015). Intervention fidelity is the degree to which an intervention is delivered as intended. The components of implementation fidelity evaluated here are: Reach (the proportion of the target group who participated in RB-ATT and their socio-demographic characteristics), Dose and Timeliness (of the intervention delivered) and Adherence/Compliance (of students to the minimum programme requirements). This process evaluation corresponds with the inputs, activities and outputs detailed in the RB-TPP logic model and interrogates the assumptions underlying the model and the linkages between the intervention components and outcomes (Fig. 1). The framework for documenting RB-TPP programme implementation and data sources is shown in Table 1. Terms are explained in Additional file 1. The study reporting adheres to the consolidated criteria for reporting qualitative research guidelines (Tong et al) (Additional file 2), and the TIDieR (Template for Intervention Description and Replication) Checklist (Additional file 3) (Hoffmann et al, 2014) has been used to describe the intervention. The Checklist for Reporting Results of Internet ESurveys (CHERRIES) (Eysenbach, 2004) guided the reporting of survey findings.

\section{Study setting and participants}

A total of 588 registered university students were listed occupants in two residences on a single UK university campus at the time of the study and eligible to participate (site 1:366, site 2: 222). Of these, 116 were not living onsite (by choice) due to the COVID-19 pandemic. There were 472 students living onsite at the time of the study (80\% occupancy; site 1: 311 , site 2: 161), of whom 464 provided informed consent to take part ( $98 \%$; site 1: 306 , site 2: 158). Students who opted out of the programme were re-located to alternative temporary accommodation during the study period. Reasons for decline were perceived risk for COVID-19, and inconvenient timing of the programme due to its proximity to academic examinations. The settings were deemed to be more 'traditional' residences with large corridors, shared facilities, communal dining and socialising models and where a prior COVID-19 mitigation approach of the small group 'student household' (e.g., in Blake et al, 2020) was less relevant. Eligible process evaluation participants were in-house students who had either taken part in or opted out of the RB-TPP, and staff with a role in intervention delivery or student support.

\section{The Intervention: Residence-Based Asymptomatic Testing Participation Pilot (RB-TPP)}

The aim of the RB-TPP was to increase and maintain participation of students in regular COVID-19 testing in university residences. The RB-TPP (fig. 1) was planned for delivery over 4 weeks in May-April 2021 and required asymptomatic students to take a saliva test for COVID-19, twice weekly for four weeks. This was combined with relaxed social restrictions 
within the residence during the study period (i.e., removing the need for 2-metre distancing between students living in the same residence), devolved local contact tracing (i.e., contacts traced locally by a university and local public health team, rather than the national Track and Trace service) and enhanced support for students who were required to self-isolate (i.e., welfare and financial support). The identification of any positive cases during this period would trigger residence surge testing, whereby all students living in the hall would then be required to test daily for seven days. Communications with students were focused on expectations (testing and social behaviour), testing processes and logistics. Communications were delivered primarily by email, supported by face-to-face communications from staff with student-facing roles, and three student ambassadors known as 'testing champions' offering peer-to-peer support and encouragement to participate. The testing service provider was the host University's flagship asymptomatic testing service (ATS), which at the time of writing was one of only eight laboratories specifically recommended for, or accredited for, COVID-19 testing in the UK. The views of university staff and students towards the ATS have been published elsewhere (Blake et al, 2020, Blake et al, 2021). Tests were non-invasive self-administered saliva polymerase chain reaction (PCR) tests for SARS-CoV-2 with samples collected and analysed in the University's laboratories. During the study period, a second confirmatory National Health Service (NHS) Pillar 2 test was required for all positive cases identified via asymptomatic tests (no longer required from July 2021). The testing service set up deployments in the dining areas of the two sites, which were staffed on Tuesdays and Fridays for the students to drop off their samples. Opening hours were initially 10:00-14:00, but hours were extended to give students greater flexibility in when they could drop off their samples - extending hours initially to 16:00, then to 19:00 after student feedback. All RB-TPP processes were overseen by the university COVID-19 Testing Operations group working in collaboration with local and national public health teams.

\section{Data collection}

We gathered quantitative measures of intervention activities (such as number of students participating in the residencebased testing participation scheme) (Carroll et al, 2007), and qualitative exploration of the interaction between the programme, how students and staff experience it, and the contextual characteristics of the two sites in which it was delivered.

\section{Implementation fidelity}

Reach Program reach was evaluated through the number of students recruited into the RB-TPP compared to the number of potentially eligible students living in one of the two participating sites in April 2021 (identified via residence manager's records). Recruitment data were collected by the COVID-19 Testing Operations Team and entered directly into a secure web-based database. Reasons for participating (or not), and characteristics of students opting in and out were collected in an end-of-programme survey.

Adherence/Compliance Participant compliance was defined as the proportion of students that completed two tests per week. Pre-defined compliance was therefore completion of 8 tests over the 4-week period. Objective data on uptake were recorded by the COVID-19 Testing Operations Team and student self-reports of reasons for compliance and noncompliance with testing, and adherence and non-adherence to pre-defined behavioural expectations were collected in an end-of-programme survey.

Dose and timeliness of intervention delivery Data related to the dose delivered (number of tests offered, total duration of intervention) and timing of intervention delivery (when tests were available, when and how results were received, additional surge testing, contact testing). Data were recorded by the COVID-19 Testing Operations Team with any reasons and challenges raised explored in the end-of-programme survey.

Online survey Students opting in or out of the intervention received an email at programme end, sent from the ATS, containing a direct link to an information sheet and online survey (Additional file 4), hosted on Jisc Online Survey platform with automatic capture of responses. Items were adapted from a prior study (Blake et al, 2020) and contained a mixture of 
closed and open-ended free-text questions. They survey contained approximately 2-4 items per page, over 19 pages. Adaptive questioning (certain items, or only conditionally displayed based on responses to other items) was used to reduce number and complexity of questions. Non-response options were included, participants could amend their answers up to the final page, and completeness checks occurred prior to submission using JAVAScript. Usability and technical functionality of the electronic questionnaire were tested before fielding. Informed consent was assumed from voluntary completion of the survey, and students received $£ 5$ as compensation for their time. Measures included sociodemographics, prior history of COVID-19 and social isolation, views towards the intervention (testing and follow-up, logistics, communication, adherence to social behaviour regulations during the intervention), COVID-19 risk perception before and after the intervention, views towards COVID-19 protective behaviours and anxiety as measured by the Generalised Anxiety Disorders Scale (GAD-7; Spitzer et al., 2006; Kroenke et al., 2007).

Student focus groups and staff interviews The qualitative arm of the study aimed to explore the impact, consequences and experiences of the staff and students involved in the RB-TPP and establish their views on all aspects of the programme and the implementation fidelity components detailed above. Students' perspectives were examined through seven focus groups planned to take place at the end of week 2 (mid-point, May 2021). This included six groups for students (opting in or out of the RB-TPP), and a single group for student ambassadors. Group size ranged from 3-6 attendees. Participants provided written and verbal consent. All students received $£ 20$ as compensation for attendance at a focus group. Staff perspectives were examined through individual interviews planned to take place in week 4-5 (end point, June 2021). Eligible participants were purposively sampled according to role (testing operations, residence management, student support). They were contacted by email and invited to take part in a focus group or interview. Those that agreed to participate provided written and verbal consent. Student focus groups were conducted by two researchers (SC, LF) and lasted between 42 and 61 minutes (mean 52 minutes). Staff interviews were conducted by one researcher (LF) and lasted between 15 and 35 minutes (mean 22 minutes). Researchers collecting and analysing data had no involvement with the testing service or university residences.

Interviewers used question guides (Additional file 5) developed by a health psychologist in consultation with the process evaluation team and members of a patient and public involvement and engagement (PPIE) group, and field notes were taken. The guide included prompts to discuss opinions about programme content, dose, delivery style, and delivery mode, as well as perceived benefits of and barriers and facilitators to participation. All interviews and focus groups were held via a video-conferencing platform, audio-recorded and transcribed.

\section{Barriers, facilitators and acceptability}

Barriers and facilitators to implementing RB-TPP, and acceptability of the programme to students and staff were identified through the student focus groups and survey, and staff interviews as detailed above.

\section{Patient and Public Involvement}

Student and staff views informed the study design and interview questioning guides at the point of study conception, via a Patient and Public Involvement and Engagement (PPIE) group. Students expressed a preference for small $(n<=6)$ focus groups, and staff preferred to participate in individual interviews. Study findings will be disseminated to all participants through this publication and lay summaries disseminated via the participating university.

\section{Data analysis}

Quantitative survey data were analysed using descriptive analysis and non-parametric tests of association (Spearman's Rho, Kendall's Tau, and Chi-Square). Qualitative data from the semi-structured interviews and focus groups were analysed by two researchers (SC, LF) using deductive and inductive coding (Braun and Clarke, 2006). First, coding was guided by the assumptions of the RB-TPP programme logic and key components of the intervention. This included: impact of the RB- 
TPP on containing the spread of COVID-19, impact on students (e.g., personal risk and wellbeing, satisfaction, social behaviours, testing processes, identifying cases, wellbeing etc), impacts on staff (e.g., personal risk and wellbeing, satisfaction, resources etc), views towards key components of the pilot (e.g., communications, ambassador role, testing process, test type, logistics, social aspects, surge testing, enhanced contact tracing, managing positive cases, isolation support), barriers and facilitators to implementation and outcome (e.g., social factors, government policy, new guidance, incidents) and future recommendations. Then an inductive approach was used to code relevant features of the data beyond the pre-defined categories. Coding was undertaken using NVivo 12 software (released March 2020) (QSR 2020). Discrepancies were discussed until consensus was reached. Themes were identified from the codes and mapped to the Capability Opportunity Motivation - Behaviour (COM-B) model (Michie et al, 2011). This model categorises behaviour (B) as the result of an individual's capability (C); opportunity (O); and motivation (M), to perform the behaviour. The behaviours of

interest for this evaluation were: (i) participation in the RB-TPP programme (student participants); and (ii) delivery of the RB-TPP (staff participants).

\section{Results}

Data were all collected from programme end. Student focus groups were conducted within one week, and staff interviews within 3 weeks. The survey closed after 3 weeks. Monitoring data relating to uptake and reach were collected concurrently. Due to a national escalation of positive cases of the COVID-19 Delta variant resulting in reduced support from the national NHS track and trace team, the RB-TPP was terminated early (after 10 days, broadly the mid-point). Testing compliance data were therefore collected only from Thursday 6th May to Sunday 16th May 2021, although the requirement for students to complete two tests per week was retained. For these purposes, any student who had tested three times or more over this period was therefore classed as fully compliant.

In this process evaluation, 152 students completed the online survey (88 women, 63 men, mean age 19.24 years) of whom 145 (95.4\% of survey respondents, $31 \%$ of RB-TPP participants) had participated in the RB-TPP. All responses were included in analysis. Total survey participation rate was $34 \%$ of RB-TPP participants. Survey participants were broadly representative of RB-TPP participants. There was a total of 30 students (14 women, 16 men, mean age 19.9 years) attending one of 7 focus groups, and 13 staff ( 7 women, 6 men) were interviewed. Staff job roles were related to the testing service (strategic and operations), hospitality, accommodation or other student support. The staff interviewed were student facing $(n=6)$ and non-student facing $(n=7)$.

\section{Implementation fidelity}

Reach A total of 464 students chose to participate in RB-TPP (site 1: 306; site 2: 158). This represented $98 \%$ of students who were resident in the two sites at initiation of the RB-TPP (and 79\% of all students listed as occupants, including those who were not present on campus at the time of the study). Survey participant characteristics are presented in Table 2, reasons for participation are shown in Table 3. There was no significant difference in the proportion of participants consenting to the RB-TPP at site 1 and site 2, or in sociodemographic characteristics of those who opted in, or out. Further details of student health and prior experience of COVID-19 are provided in Additional file 6.

Table 1. Framework for documenting RB-TPP programme implementation and data sources 


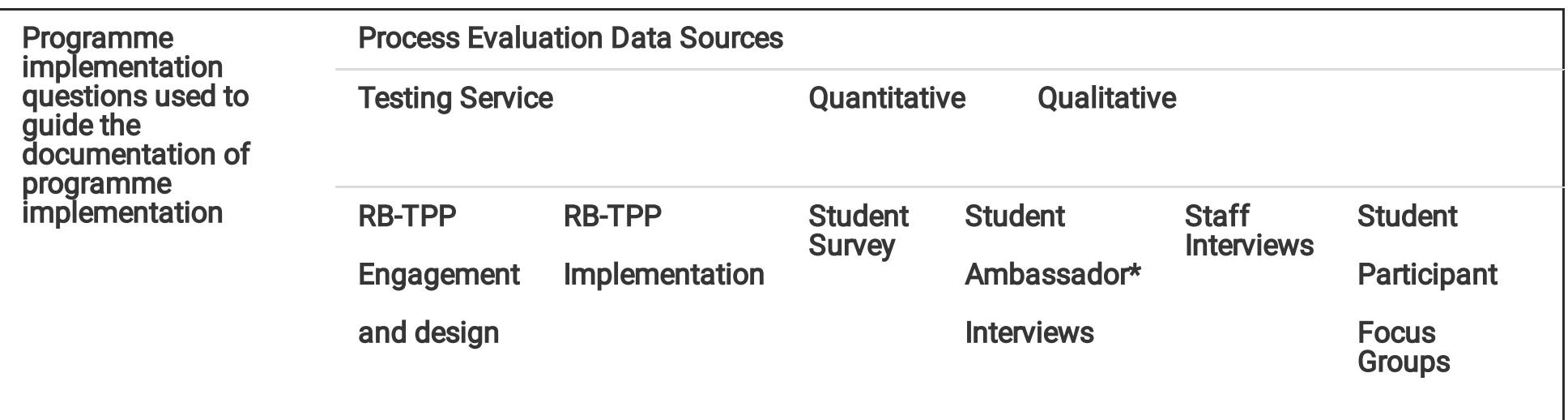

\section{Programme design}

1. Who were the target participants? What was the uptake and reach?

2. What were the target settings? Did settings change over time?

3. What theoretical model/theory-ofchange were the strategies based on?

3. What essential elements were to be delivered in the programme?

\section{Testing service} provision

\section{What selection} process was used to identify the provider?

What were the credentials of providers?

\section{What information} did the testing service providers communicate to students (what was the content and format, and were there any changes over time?)

\section{Recruitment to RB-TPP}

6. How were students recruited as

participants?

\section{What was the} nature of the relationship between the student participants and the researchers or 
institutions involved in

the programme?

Tailoring, messaging,

incentives

8. Which behavioural components are

selected?

9. What are the reasons for that selection? (what goals are targeted)?

10. What, if any, other goals and strategies are proposed by programme leaders and ambassadors supporting uptake, engagement and adherence?

\section{Programme delivery}

11. What method was used to specify and direct the implementation?

\section{How long were} participants involved?

13. What were the testing and social

behaviour

expectations?

\section{To what extent} were the essential elements delivered?

How were they

monitored/measured?

15 . Were there any planned changes made to the RB-TPP while

it was in progress?

Why?

\section{Were there any} unplanned changes? What happened?

\section{Context}

17. What was the culture and

overarching context of

the participating agencies at the start of the intervention?

18. Were there any changes/initiatives

during the programme

$\checkmark \quad \checkmark \quad \checkmark r \quad \checkmark \quad \checkmark$

$\checkmark$

$\checkmark$

$\checkmark$

$\checkmark$

$\checkmark \quad \checkmark$ 
that may have

affected responses to

the intervention?

19. What were the immediate contextual

conditions

around the testing?

\section{Participation}

20. Who was invited to participate: numbers, locations, campuses, institution(s)?

21. How many potential students engaged in RB-TPP? Who were they?

22. What proportion of targeted students engaged (one PCR test) or were fully compliant (all PCR tests offered $)^{1}$ ?

23. Did key people (public health leaders or topic specialists) support or advocate the programme?

\section{Responses to} programme activities

24. How did students participate in components of the programme?

25. How satisfied were participants with components of RBTPP?

26. Did students or staff identify or anticipate any changes in response to RB-TPP programme activities?

\section{Intervention} improvements

\section{What}

improvements to the intervention design and/or

implementation are suggested by this data?

29. What lessons might be relevant to

$\checkmark \quad \checkmark \quad \checkmark r$

$\checkmark \quad \checkmark \quad r$

$\checkmark$

$\checkmark$


Note: *Student Ambassador Role: peer-to-peer recruitment (engagement) and implementation of social distancing (adherence). Testing: ${ }^{1}$ non-invasive saliva polymerase chain reaction (PCR) tests for SARS-CoV-2 with samples collected and analysed in the University's laboratories.

Of survey respondents, 24 students undertaking paid or voluntary work, of whom 12 identified themselves as key workers (e.g., health or social care, food chain supplies, public service), regularly coming into close contact (<2metres) with others outside of the residence. Although reasons for participation were diverse, the three most common reasons for participating were positive: to contribute to the national efforts to contain COVID-19, helping to keep campus safe for everyone, and getting to know other students better (Table 3). A minority participated to avoid negative consequences (e.g., perceived pressure, not wishing to relocate during the intervention). Seven survey respondents had opted out of the programme (5M, $2 F ; 1$ keyworker). Over one third of survey respondents had tested positive for COVID-19 at some point during the pandemic and $83.2 \%$ had been required to self-isolate at least once before. Of those who opted out, only two had previous experience of self-isolating and none had tested positive for COVID-19 previously. All 7 students reporting an existing physical health issue had participated in the pilot. One fifth of the sample $(n=29,19.3 \%)$ reported a prior history of mental health issues. All of the survey respondents reported symptoms of anxiety on GAD-7, and this was moderate to severe in $45.9 \%(n=68)$ students who met the screening threshold for general anxiety disorders (score >=10 on the GAD-7; Spitzer et al., 2006; Kroenke et al., 2007).

Table 2. Characteristics of RB-TPP participants. 


\begin{tabular}{|c|c|c|c|}
\hline & \multicolumn{3}{|l|}{$\mathrm{n}(\%)$} \\
\hline & Total sample & $\mathrm{P}^{\mathrm{a}}$ & Non- $\mathrm{P}^{\mathrm{b}}$ \\
\hline Gender & $N=151$ & $n=144$ & $\mathrm{n}=7$ \\
\hline Female & $88(58.3)$ & $86(59.7)$ & $2(28.6)$ \\
\hline Male & $63(41.7)$ & $58(40.3)$ & $5(71.4)$ \\
\hline Ethnicity & $N=150$ & $n=143$ & $\mathrm{n}=7$ \\
\hline White & $129(86.0)$ & $123(86.0)$ & $6(85.7)$ \\
\hline Mixed & $5(3.3)$ & $(5,3.5)$ & $1(14.3)$ \\
\hline Asian or Asian British & $11(1.3)$ & $10(7.0)$ & \\
\hline Black or Black British & $2(1.3)$ & $2(.7)$ & \\
\hline Middle Eastern or Middle Eastern British & $1(.7)$ & $1(.7)$ & \\
\hline Prefer not to say & $2(1.3)$ & $2(1.4)$ & \\
\hline International Student & $N=151$ & $n=144$ & $\mathrm{n}=7$ \\
\hline Yes, European Union & $9(6.0)$ & $9(6.3)$ & 0 \\
\hline Yes, International & $6(4.0)$ & $6(4.2)$ & 0 \\
\hline No, Home Student & $136(90.1)$ & $129(89.6)$ & $7(100)$ \\
\hline Year of Study & $N=151$ & $n=144$ & $n=7$ \\
\hline Foundation & $2(1.3)$ & $2(1.4)$ & 0 \\
\hline $1 \mathrm{st}$ & $140(92.7)$ & $135(93.8)$ & $5(71.4)$ \\
\hline 2nd & $2(1.3)$ & $2(1.4)$ & 0 \\
\hline $3 r d$ & $1(.7)$ & 0 & $1(85.7)$ \\
\hline 4th & $3(2.0)$ & $3(2.1)$ & 0 \\
\hline 5th & 0 & 0 & 0 \\
\hline Postgraduate & $3(2.0)$ & $2(1.4)$ & 0 \\
\hline Accommodation during term-time & $N=151$ & $n=144$ & $\mathrm{n}=7$ \\
\hline University Halls of Residence & $150(99.3)$ & $144(100)$ & $6(85.7)$ \\
\hline Temporary, alternative accommodation & $1(.7)$ & 0 & $1(14.3)$ \\
\hline
\end{tabular}

RB-TPP: Residence-Based Testing Participation Pilot; ${ }^{a}$ PIP: Participated in RB-TPP; ${ }^{b}$ Non-P: Did not participate in RB-TPP Table 3. Reasons for participation in the RB-TPP ( $n=145)$. 


\begin{tabular}{|l|l|}
\hline What were your main reasons for taking part? & $\%$ \\
\hline To protect yourself & 36.6 \\
\hline To protect your family & 22.8 \\
\hline To protect local communities & 29.7 \\
\hline To reassure myself about my health status & 35.2 \\
\hline To reassure my family about my health status & 23.4 \\
\hline To contribute to national efforts to contain COVID-19 & 58.6 \\
\hline Helping to keep campus safe for everyone & 56.6 \\
\hline Learning something new about COVID-19 itself & 6.2 \\
\hline Learning something new about CovID-19 testing & 6.2 \\
\hline Getting to know other students better & 51.0 \\
\hline Getting to know university staff better & 7.6 \\
\hline Being involved in CoVID-19 research & 39.3 \\
\hline Having pride in my University & 17.2 \\
\hline Other & 5.5 \\
\hline $\begin{array}{l}\text { \% of respondents who selected each answer option (100\% would represent that all respondents to the item selected } \\
\text { this option). }\end{array}$ \\
\hline
\end{tabular}

\section{Adherence/Compliance}

\section{Saliva Testing}

Intervention monitoring data showed that 409 of the 464 intervention participants (88\%; site 1: 278, site 2: 131) completed at least one test during the data collection period. A total of 213 (site 1: 134, site 2: 79; $46 \%$ of all participants; $52 \%$ of those who tested) were classed as fully compliant. There were no reactive tests identified. Of the 145 respondents, $64.1 \%$ $(n=93)$ were extremely and $33.8 \%(n=49)$ somewhat confident in the results of their asymptomatic saliva tests. Almost all students were satisfied with the physical process of taking a saliva test $(95.9 \%, n=139 / 145)$. Non-compliance was largely due to students being away, or missing drop-off times due to academic commitments.

\section{Correlates of testing frequency}

A larger number of tests completed was associated with increased satisfaction with their ability to interact with others in their hall $(r=-.180, p=.031, \mathrm{n}=145)$, although the magnitude of this association is small. Students who were more satisfied with the test drop-off and pick-up processes were more likely than those dissatisfied to report full test compliance during the pilot $\left(X^{2}(1, n=143)=4.917, p=.027\right.$, effect size (Cramer's $\left.\left.V\right)=.185\right)$. Students who reported higher levels of worry about the risk of getting COVID-19 completed a greater number of tests during the pilot (ie., were more adherent to testing) ( $r=$ $-.151, p=.043, \mathrm{n}=138)$. A higher number of tests completed during the pilot was significantly associated with increased positive perceptions of social distancing $(r=.178, p=.033, n=144)$, face coverings $(r=.227, p=.006, n=144)$, and hand washing $(r=.165, p=.047, n=144)$ as essential controlling measures for COVID-19.

\section{Social behaviours: social distancing, self-isolation, and face coverings}


Of respondents, $88.3 \%(n=128 / 145)$ were somewhat or extremely satisfied with level they were able to interact with other people in their hall of residence during this time. Almost all $(97.9 \%, n=141)$ felt that relaxed social distancing in halls was acceptable; many indicated that social contact was happening regardless and better to be sanctioned: 'we already have unavoidable contact'. There was an overwhelming perception that the benefits of social interaction to mental health outweighed the risk of virus transmission which was perceived to be low. Three-quarters $(75.5 \%, n=108)$ of students reported always maintaining social distancing (two metres) when interacting with staff, out of 'courtesy'and 'respect'. An estimated $92.4 \%(n=133)$ indicated that they had adhered to social distancing and all other COVID-19 security rules outside the hall environment 'to protect others'. All (100\%) students reported they did not have to self-isolate during the pilot $(n=144)$. Three-quarters $(73.4 \%, n=80)$ of students indicated they were either 'extremely' or 'somewhat satisfied' with the University's support offer for students required to self-isolate. Over half $(7.3 \%, n=82)$ reported always wearing a face covering in communal areas in their hall. Non-compliance with behavioural regulations (e.g., face coverings, social distancing) was largely due to misunderstanding (of students and some staff groups) what was allowed and where, and frequent changes or inconsistency in messaging. Complacent attitudes and misbehaviour of some students caused frustration among those conforming to the rules.

\section{Student satisfaction, barriers and facilitators}

Of respondents, $88.1 \%(n=126)$ would take part in a similar COVID-19 testing participation scheme in future. Eight out of ten respondents $(82.5 \%, \mathrm{n}=118)$ would recommend it to their peers. Dissatisfaction in the minority largely stemmed from communication issues (with regards conflicting information, perceived pressure or hostility), and a mismatch between some students' expectations of the pilot and the reality of delivery (with regards incentives, and social behaviour regulations). Barriers and facilitators to participation in, and delivery of, RB-TPP are mapped to the COM-B framework (Michie et al, 2011). (Table 4).

Dose and timeliness Tests were provided to students each week (2 per week) in line with planned delivery timing (scheduled days/times). Weekly dose and timeliness therefore aligned with the pre-determined plan. However, overall dose was not per protocol; early termination of the RB-TPP means that the full testing 'dose' (8 tests) was not possible; evaluation is therefore based on a reduced dose ( 3 tests) across a shorter intervention period (10 days).

The majority of students were satisfied with test pick-up and drop-off processes (84\%, $n=121 / 144)$ and the communication around test results $(96.6 \%, n=140 / 144)$. Any dissatisfaction was generally due to a perception of poor communication around changed procedures, inappropriateness of drop-off timings due to academic commitments. If a positive case was identified in a student's hall during the pilot, all students in hall were required to take an additional test that week (surge testing). The vast majority, $97.1 \%(n=136)$ of students participating in the pilot thought this plan was acceptable, although surge testing did not occur since there were no positive cases identified during the intervention period.

"I thought it was a good thing because it spread so much in the October, November time so I felt like it definitely would have halted it." [FG5, S3]

Students who were identified as a close contact of a person who tested positive were required to test every day for 7 days. An estimated $96.4 \%(n=134)$ felt that the 7-day contact testing frequency was acceptable: "small price to pay for protecting others from covid." Students who were identified as a close contact of a person who tested positive did not need to isolate if their tests over the next seven days were negative, and this was viewed to be acceptable $(93.5 \%, n=130 / 142)$. Only one (.7\%) individual reported experiencing this process as they were identified as a close contact of a positive case. A further case $(.7 \%)$ indicated they preferred 'not to say'.

Table 4. Barriers and facilitators to participation in and delivery of RB-TPP, mapped to the COM-B Framework 


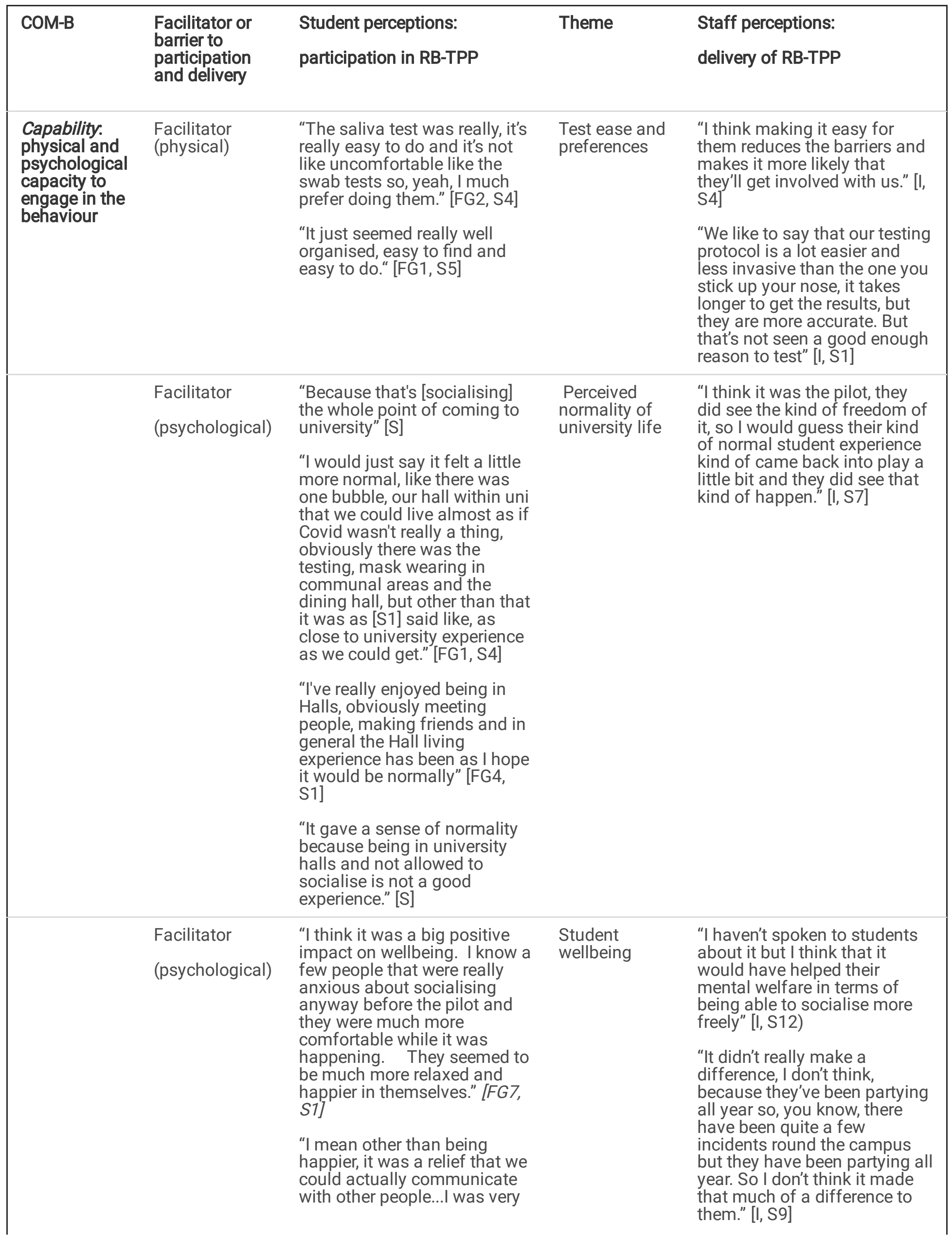

Page 15/31 
happy that you know, it occurred." [FG1, S1]

"I went to dinner alone for 5 months straight, until this pilot study came in. It was definitely less isolating". [S]

"Felt nice for normality and to speak to people l'd seen around but never been able to speak to, definitely improved my mental health" [S]

"more is risked by allowing students to feel isolated in their tiny rooms with only 5 in their household and letting their mental health plummet" [S]

Facilitator
(psychological)

"[before the pilot] They didn't really want to go out of their way to get tested, especially as they'd been through the really severe isolation, they weren't allowed to leave at all, and they don't kind of want to go through that again." [FG1, S5]

"[before the pilot] I think it was a very real fear of it's just not going to be a good time if you quarantine" [FG4, S2]

"[with surge testing in place]...they don't want to be the reason that the rest of their household has to stay indoors for 10 days and not see anyone or do the things that they've got planned. So I think the surge testing was actually quite a good idea to kind of test to see how the spread would happen." [FG7, S2]

Reducing fear of selfisolation

n
"I suspect beforehand there would have been a bit of taboo almost about going and testing at the risk of them becoming positive and then locking down households. If you think in a house of six, one of you goes, gets tested and then the rest of them have to isolate, the other five might be a little bit miffed at that." [I, S4]

"And then we've got the process in place now, if we do have a positive we don't have to isolate the whole household, you know, that person then just gets moved to the [alternative accommodation], taken out the equation, and then everybody just has to test for one week and then negatives are coming back in 24 hours, so really they don't have to isolate for very long, it's only a 24 hour period where at the beginning of the academic year we had 97 and 92 households in isolation for ten days." [I, S3]

Barrier

(psychological)
"They [other students] said, 'well I don't see the point in testing because there's no cases on campus anyway so why should we test?"' [FG3, S1]

"It felt basically the same from my point of view. I think other people did mix more but, yeah, they hadn't really been enforcing the household only mixing beforehand anyway, everyone had just been sitting in the dining room next to each other for a while before,
Complacency and indifference “...there was some feedback that some students really didn't quite get the point of why we were doing it, why they were doing the testing" [I, S12]

"The students weren't aware of the bigger picture here what was going on really, because they're obviously in their own household, they're on campus, they're in their little bubble and really it's a much bigger thing that we're trying to protect." [I, S3] 
so it didn't feel like it changed

that much" [FG2, S4]

"It needs to be a bit more

forceful in 'look, you're either

doing this or you're not',

because otherwise I think that

kind of - what's the word -

just that indifference will set

in and people stop doing it."

[FG2, S5]

$\begin{array}{ll}\begin{array}{l}\text { Opportunity. } \\ \text { external }\end{array} & \text { Facilitator } \\ \text { factors that } & \text { (testing } \\ \text { make the } & \text { service) } \\ \text { behaviour } & \\ \text { possible } & \end{array}$

"now since it's [test site]

literally just inside the Hall, so

it's a lot more convenient."

[FG3, S6]

"It just seemed really well organised, easy to find and easy to do." [FG1, S5]

"test results were always given out quickly" [S]

\section{Convenience} and efficiency of testing

"The very fact that we were in the Halls of Residence in a location where the footfall was really good, people were going past all of the time, I was surprised how important that was and make it easier for people to drop samples off, yeah, I was surprised about that." [I, S2]

"Well I think the testing team are brilliant. So I think anything relating to the process of the testing was always done brilliantly and they would adapt to whatever". [I, S12]

"the testing team were really good on site as well, you know, they'd just turn up and say 'we're here for the kit' and off they go, they were really good, showed us how to use all the laptops, how to record the samples." [I, S3]

$\begin{array}{ll}\begin{array}{l}\text { Facilitator } \\ \text { (testing }\end{array} & \text { "I also appreciated how } \\ \text { service) } & \text { transparent the university was } \\ & \text { with testing figures" [S] } \\ & \text { "It was pretty clear and we got } \\ & \text { regular updates on the } \\ \text { progress of the participation" } & \text { [S] }\end{array}$

Transparency

".. keeping the comms a bit more bitesized and even if there had have been, if we'd had the time to do infographics and things" [I, S7]

$\begin{array}{ll}\text { Facilitator } & \text { "I thought it was pretty } \\ & \text { straight forward actually, the } \\ \text { (testing } & \text { information everything, um... } \\ \text { service) } & \text { the emails were pretty } \\ & \text { frequent everything like that, } \\ & \text { so I think we had all the } \\ & \text { information that we needed." } \\ & {[F G 1, S 1]}\end{array}$

"I definitely want to know what'll happen if someone tested positive in the Hall, what that means for me." [FG2, S5]

"I feel everything was well communicated, if any changes occurred, we would be notified about these very
Clear and

regular

information
"I think the university's messages are really good, it's just that they're having to respond to changes that have come from government." [l, S11]

"The communication team did well communicating what they had to communicate but for ever changing times, needing to clarify behaviours and everything just led to excess communications being sent out and I imagine that didn't go down too well with students." [I, S6] 
quickly, we would always be reminded to collect and hand in our test samples. So overall, information was very well communicated". [S]

\begin{tabular}{|c|c|c|c|}
\hline $\begin{array}{l}\text { Facilitator } \\
\text { (peers) }\end{array}$ & $\begin{array}{l}\text { "during the pilot the } \\
\text { adherence was pretty good... I } \\
\text { think overall we did pretty well } \\
\text { with everyone testing and } \\
\text { everything like that." [FG1, S1] }\end{array}$ & $\begin{array}{l}\text { Testing as a } \\
\text { social norm }\end{array}$ & $\begin{array}{l}\text { "...going into the new } \\
\text { academic year when you've } \\
\text { got a new Halls intake, } \\
\text { pushing normalisation of } \\
\text { testing I think is really } \\
\text { beneficial potentially." [I, S4] } \\
\text { "The positive of the pilot was } \\
\text { that we had far greater, a far } \\
\text { greater amount of testing } \\
\text { within them two halls than } \\
\text { we've seen across } \\
\text { accommodation at any point. } \\
\text { I think we got } 60,70 \text { per cent } \\
\text { within the halls which just } \\
\text { wouldn't have happened } \\
\text { without the pilot so that was } \\
\text { the positive." [I, S6] }\end{array}$ \\
\hline $\begin{array}{l}\text { Facilitator } \\
\text { (peers) }\end{array}$ & $\begin{array}{l}\text { "it was a great opportunity to } \\
\text { be able to actually meet other } \\
\text { people in, um, in a more } \\
\text { secure environment and } \\
\text { without having to breach } \\
\text { Covid restrictions, um or kind } \\
\text { of standing outside in the rain } \\
\text { talking to people" [FG1, S5] } \\
\text { "I've really enjoyed being in } \\
\text { Halls, obviously meeting } \\
\text { people, making friends and in } \\
\text { general the Hall living } \\
\text { experience has been as I hope } \\
\text { it would be normally" [FG4, } \\
\text { S1] }\end{array}$ & $\begin{array}{l}\text { Creating } \\
\text { social } \\
\text { opportunities }\end{array}$ & $\begin{array}{l}\text { "There was positive impact } \\
\text { because we definitely seen } \\
\text { them socialising more, we } \\
\text { opened up more of our areas } \\
\text { so they could socialise, we } \\
\text { opened the bar up at [site 2] } \\
\text { for use so they could use the } \\
\text { bar as a bar service } \\
\text { throughout the period, so they } \\
\text { gained more facilities for } \\
\text { starters, more socialising } \\
\text { facilities and they can } \\
\text { socialise with more people." [I, } \\
\text { S3] }\end{array}$ \\
\hline $\begin{array}{l}\text { Barrier } \\
\text { (testing } \\
\text { service) }\end{array}$ & $\begin{array}{l}\text { "... the submitting part is the } \\
\text { hardest part because the } \\
\text { timing isn't really suitable for } \\
\text { people who've got live } \\
\text { sessions" [FG3, S6] } \\
\text { "I saw a lot of people handing } \\
\text { in tests but then not being } \\
\text { given another one to do" [FG7, } \\
\text { S1] } \\
\text { "People would go home } \\
\text { without telling the uni and } \\
\text { they would be counted as not } \\
\text { having a test despite them not } \\
\text { being able to" [FG1, S3] }\end{array}$ & $\begin{array}{l}\text { Logistical } \\
\text { challenges }\end{array}$ & $\begin{array}{l}\text { "we learned as we went } \\
\text { through the timings that we } \\
\text { were there - with the greatest } \\
\text { of respect there wasn't a lot of } \\
\text { point in us being there at } \\
10 a m \text { in the morning! There } \\
\text { was a lot of benefit from us } \\
\text { being there at five o'clock in } \\
\text { the evening when it was the } \\
\text { first opening of the doors for } \\
\text { dinner. And that was an ideal } \\
\text { time. And we learned that and } \\
\text { perhaps we should have } \\
\text { thought of that right at the } \\
\text { very start." [I, S2] }\end{array}$ \\
\hline $\begin{array}{l}\text { Barrier } \\
\text { (testing } \\
\text { service) }\end{array}$ & $\begin{array}{l}\text { "information about the timing } \\
\text { and place for picking up and } \\
\text { dropping off tests kept } \\
\text { changing" (S) } \\
\text { "I didn't feel like it was very } \\
\text { clear, like, the extra things we } \\
\text { were allowed to do, we were } \\
\text { just sort of, it felt like we were } \\
\text { told, like, vaguely what we }\end{array}$ & $\begin{array}{l}\text { Changing } \\
\text { processes and } \\
\text { mixed } \\
\text { messages }\end{array}$ & $\begin{array}{l}\text { "If you're changing the } \\
\text { goalposts every week, that } \\
\text { gives my team a really tough } \\
\text { job because you're having to } \\
\text { make people understand } \\
\text { something new every week } \\
\text { and they're just going to } \\
\text { eventually switch off because } \\
\text { you've only got a few } \\
\text { opportunities." [l, S6] }\end{array}$ \\
\hline
\end{tabular}


were allowed to do but it wasn't very clear" [FG2, S4]

"Personally in [site 1] we had a couple of incidents where testing times weren't clearly communicated between the testing team and the students." [FG1, S5]

"The second day of pilot we were in a room with eight people who were all in [site 1] and we got kicked out by a security guard. When I asked him why because we were doing a pilot scheme he said ' I don't know, l've not been told about it'." [FG5, S2]

"Felt like there was a lot of miscommunication between security and the organisers as security kept trying to enforce normal social distancing rules". [S]

"I think if it was to be in halls again, it's just making things much more black-and-white so that the students know exactly what their rules are and what the expectations are and not setting the expectation crazy high." [I, S7]

"You need to have a consistent message throughout for that to get through to people and for people to really understand it" [I, S6].

"There was a bit of confusion over what they were allowed to do, what they weren't allowed to do, and you've got two security people, you've got university security, you've got [company name] and I'm not sure they were always on the same page and I'm not sure security was comfortable with going in and dealing with stuff." [I, S4]

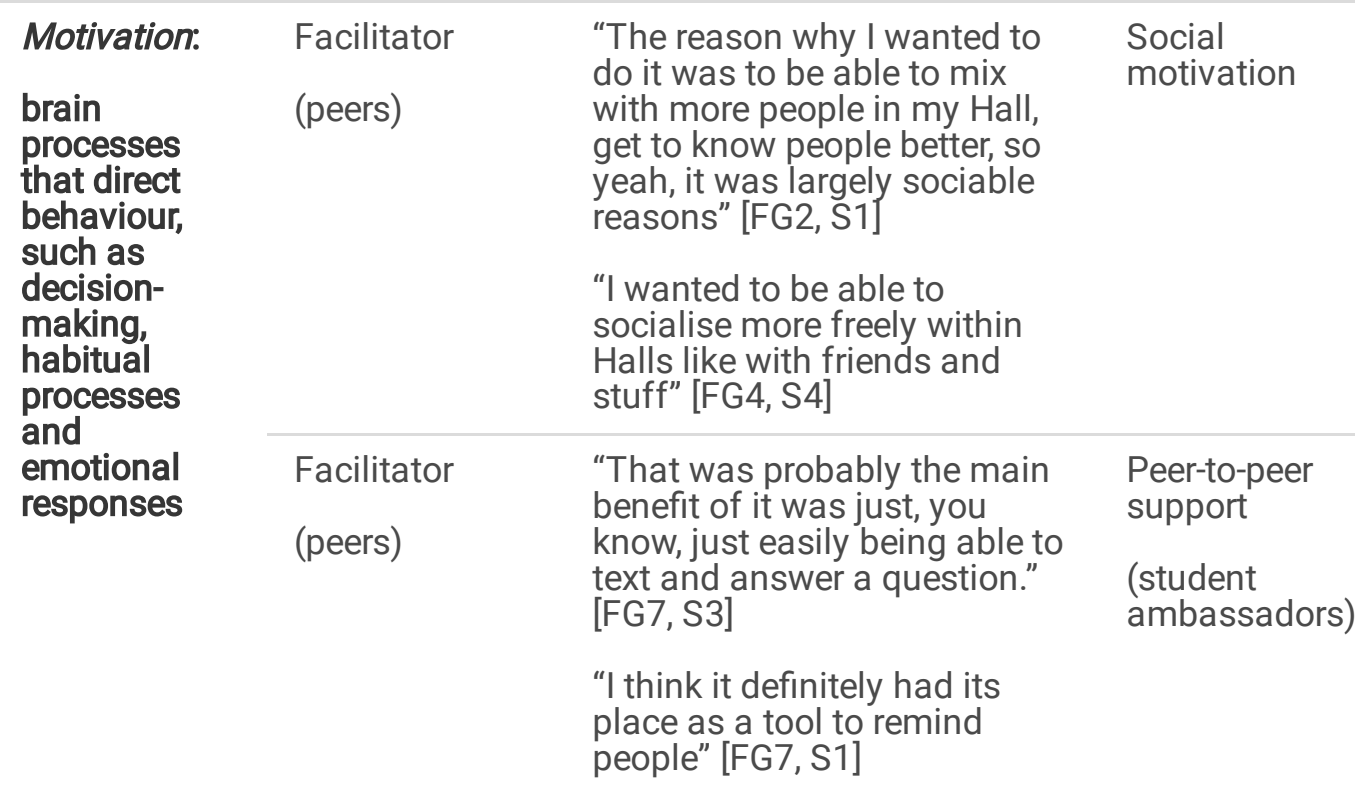

Facilitator

(staff) [punitive] "My reason for taking part is because I had a guy, there was just some guy that was coming round knocking on everyone's doors saying that we'd be relocated from the Hall if we didn't participate, so that sort of
"So it's about telling them why they should be tested every day so they can socialise and have a more normal university life." [I, S9]

"We had champions recruited to help and I think they were great because ... it's very important to know what's the view on the ground from their perspective and having those testing champions was a fantastic link to be able to understand what was going on from the students' point of view." [I, S8]

"it's showing that the staff and students are working together and it shows student voice and also where the authority or the boundaries are. Involving people, I think is the key." [I, S11]

Practical motivation
Anything from staff to suggest they thought students felt under pressure to take part, or weren't?

Staff didn't mention the feeling of being under pressure to participate 
scared me into doing it." [FG4,

S4]

[punitive] "communications

about the Pilot were partisan;

there was immense pressure

to participate". [S]

\begin{tabular}{|c|c|c|}
\hline \multirow[t]{5}{*}{$\begin{array}{l}\text { Facilitator } \\
\text { (self) }\end{array}$} & $\begin{array}{l}\text { "I really felt the relaxed } \\
\text { restrictions during the testing } \\
\text { pilot helped um, where mixing } \\
\text { between households was } \\
\text { inevitable, I felt it was } \\
\text { probably a lot safer during the } \\
\text { pilot" [FG1, S2] }\end{array}$ & \multirow[t]{5}{*}{$\begin{array}{l}\text { Safety } \\
\text { perception }\end{array}$} \\
\hline & $\begin{array}{l}\text { "I felt safe knowing that } \\
\text { everyone had been tested." } \\
\text { [FG6, S2] }\end{array}$ & \\
\hline & $\begin{array}{l}\text { "Felt safe interacting knowing } \\
\text { there were no cases in the } \\
\text { hall" [S] }\end{array}$ & \\
\hline & $\begin{array}{l}\text { "I feel safest on campus than } \\
\text { anywhere else" [S] }\end{array}$ & \\
\hline & $\begin{array}{l}\text { "it did feel a bit unsafe as it's } \\
\text { quite a big hall and knowing } \\
\text { anyone could mingle and get } \\
\text { ill was concerning" [S] }\end{array}$ & \\
\hline \multirow[t]{2}{*}{$\begin{array}{l}\text { Facilitator } \\
\text { (community) }\end{array}$} & $\begin{array}{l}\text { “... by testing twice a week, if } \\
\text { then I'm then at less risk as } \\
\text { well if I'm negative of passing } \\
\text { it on to other people, so yeah, } \\
\text { that was it for me." [FG2, S1] }\end{array}$ & \multirow[t]{2}{*}{$\begin{array}{l}\text { Societal } \\
\text { responsibility }\end{array}$} \\
\hline & $\begin{array}{l}\text { "And then with the testing } \\
\text { twice a week I suppose if } \\
\text { there was a case it would be } \\
\text { caught more quickly and then } \\
\text { if there was an outbreak it } \\
\text { could be contained quicker as } \\
\text { well." [FG2, S2] }\end{array}$ & \\
\hline
\end{tabular}

"Yeah, I think it's a good idea (testing). Like I say, it made the staff feel safe, it made us feel safe, and I'm hoping it made the students feel safe as well. There are a lot of students who are sensible and behaved, so I'm hoping that it made them feel safe as well." [Staff member
"I think it's very important to controlling the virus within universities. It keeps us ahead of the virus. In terms of knowing when an outbreak has occurred, it gives us more time to get it under control so I think it's an important part of getting universities back to you know some kind of normal." [I, S6]

$\begin{array}{ll}\text { Facilitator } & \text { "quite liked the incentives they } \\ \text { gave us, like, with the stats } & \text { Incentivisation } \\ \text { and also the little goody bags } \\ \text { they gave us, that was pretty } \\ \text { good." [FG4, S5] } \\ \\ \text { "It was only until it was known } \\ \text { that there was food bags } \\ \text { when students started to get } \\ \text { tested." [S] }\end{array}$

"At the end of the day I think it's wrong to incentivise it, because I think that people should be doing it as a norm, and I don't see a problem in doing it, as normality is once a week you do a test. To me that doesn't seem like we're asking anything really hard of anyone to do, but it's a shame that we have to incentivise things in that way." [I, S10]

\section{Barrier \\ (university)}

"the food bags weren't enough. It wasn't like enough but it didn't encourage them to get out of bed to drop off their samples and stuff." [FG6, S2]
Lack of incentivisation
"And the incentive wasn't there for them because they'd already been mixing all year, you know, we're always fighting the fight, you know, 'no you've got to split up, no you've got to stay together in your household', so from the start it's been difficult for us that way and there was no 


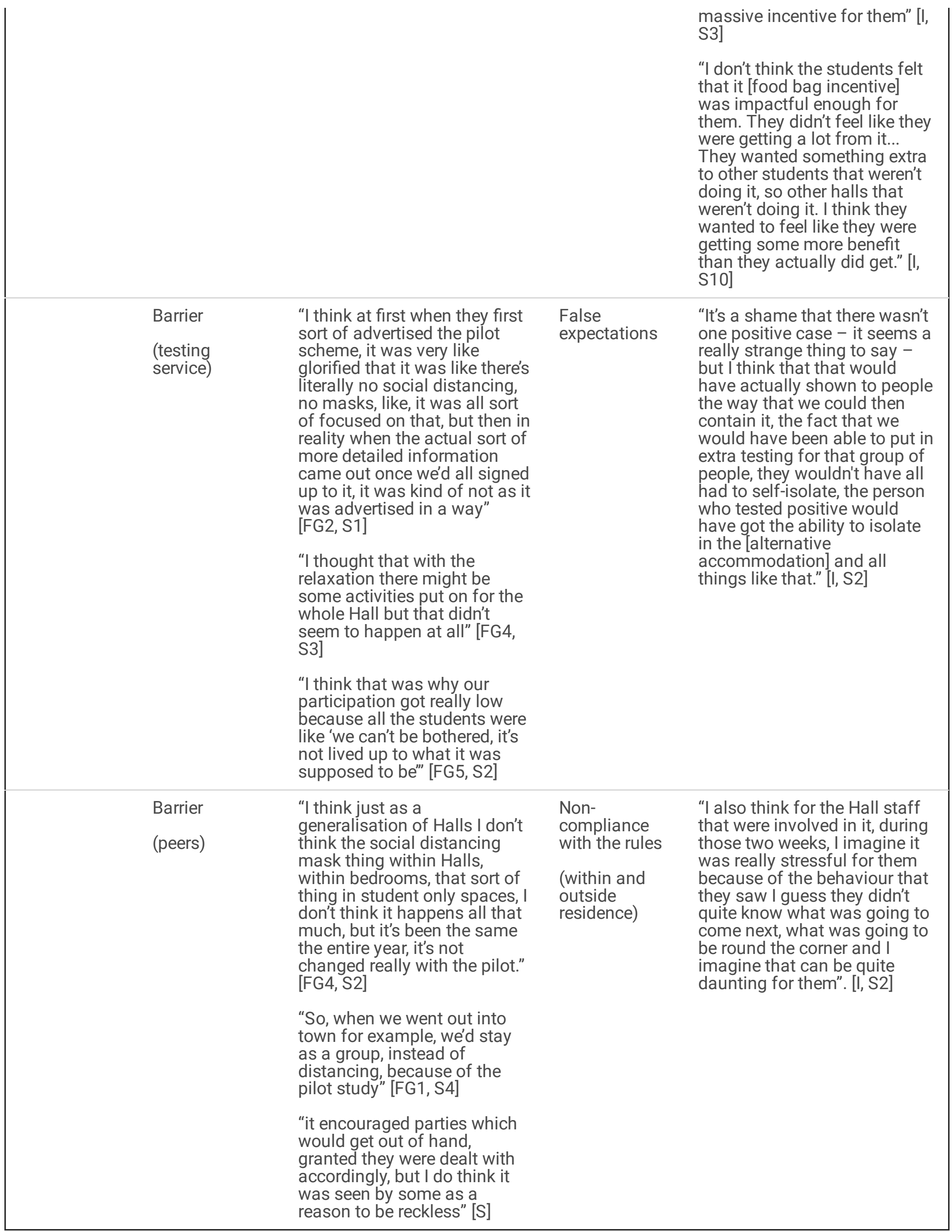


Data source: S, Survey (students); FG, Focus group (students); I, Interview (staff). This table is based on the COM-B framework (Michie et al, 2015): Capability (C), Opportunity (O), Motivation (M) and Behaviour (B).

\section{Discussion}

To our knowledge, this is the first process evaluation of a residence-based COVID-19 testing participation intervention in a university campus setting. The RB-TPP had high uptake and fidelity, resulted in a dramatic increase in the proportion of students engaging in surveillance testing, and played a significant role in students' mental wellbeing.

Uptake of the RB-TPP was high across both sites (98\% participation of in-house students, $79 \%$ of listed occupants) with high engagement in testing ( $88 \%$ of programme participants testing, compared with $5 \%$ pre-intervention), albeit only half ( $46 \%$ of participants, $52 \%$ of testers) were fully compliant with the twice-weekly testing frequency. Based on the increase in testing uptake, staff and students viewed the RB-TPP to be successful despite not meeting the $90 \%$ target, and this predetermined target was perceived by interviewees to be too high. Most of the student participants indicated they would take part again and would recommend the initiative to others. Students found the saliva test itself to be acceptable for regular testing; saliva testing for SARS-CoV-2 has been found to be a useful and acceptable tool for use in a mass screening context (Nacher et al, 2021; Tsang et al, 2021; Blake et al, 2020; Zimba et al, 2020).

The RB-TPP was largely implemented as planned. However, at the time of intervention delivery, there was a national surge in cases of the B.1.617.2 (delta) variant of SARS-CoV-2. The delta variant is associated with more severe disease than the previously dominant alpha (B.1.1.7) variant as determined by twice the relative risk of hospital admission (Twohig et al, 2021); positive cases had been identified in the region. Due to this, NHS Test and Trace (national public health team) requested early termination of the programme as they were unable to commit to supporting the RB-TPP through this critical time. Early termination of the programme meant that fewer tests were available overall due to a shorter intervention period. Since there were no reactive tests, surge testing and local contact tracing for positive cases were not required and so evaluation of these approaches 'in action' was not possible. However, students and staff held positive views towards the planned approaches.

University staff highlighted that using an accredited asymptomatic test would reduce the lag in isolating positive cases, through removal of the need to undertake a confirmatory test. This was subsequently resolved, since the university ATS used here was recommended for accreditation by UKAS (the National Accreditation Body for the UK) in July 2021, accelerating the containment process and removing the burden of confirmatory tests for national testing services. The original (pre-accreditation) process was that a positive PCR test with the ATS would lead to a request (with no legal grounds) for the individual to isolate and take a government Pillar 2 PCR confirmatory test. Therefore, the time from the initial saliva test in the RB-TPP to the result of the confirmatory test could be many days or even a week. After the recommendation for accreditation of the service was in place, the new approach considerably speeded up the process. Going forwards, a positive PCR test result from the ATS resulted in immediate notification of the individual who was then required to isolate by law (as the result was then equivalent to that of a government PCR test). In parallel, Public Health England (PHE) was notified of the positive result in order that further actions could be taken (i.e., identification and notification of close contacts), which happened the day after ATS sample provision.

Students were personally motivated to take part in the RB-TPP by the perceived safety of regular testing, societal responsibility to protect others, and a strong desire to socialise. These factors have previously been identified as important in SARS-CoV-2 testing uptake in higher education settings (Blake et al, 2020 a,b). Engagement in the programme was primarily facilitated by the positive impact of RB-TPP on students' mental wellbeing, stemming from a reduced fear of selfisolation (regular testing of close contacts of positive cases, instead of self-isolation), social contact within their accommodation and a perceived return to normal university life. Sanctioning social contact was well received by the vast majority, despite perceptions from some students that the RB-TPP did not meet all their expectations with regards

Page 22/31 
residence-wide social events. Motivation to participate was further enhanced through the involvement of student ambassadors to assist with communications and provide peer-to-peer support. Student ambassadors have been used successfully to raise health-awareness or advocate health screening programmes in educational settings (e.g., Long et al, 2021; Cerise et al, 2021: COVID-19 vaccination; O'Donnell et al, 2021: COVID-19 communication and mitigation behaviours; Arnold et al, 2021: HPV vaccination; Zhao et al, 2019: flu vaccination). Our findings contribute to an emerging evidencebase advocating the role and impact of peer-to-peer student health ambassadors on campus to mitigate the spread of COVID-19 (Lanou et al, 2021). Views towards the provision of small incentives to maximise engagement in the programme were mixed. Incentives were perceived as either 'motivating', or 'not enough' (by students), 'lacking' or 'inappropriate' (by staff).

Adherence to testing was satisfactory, and individual adherence was likely to be higher than documented, since students who left the residence during the study period or could not locate a test kit due to logistic issues were not excluded from test uptake figures. Adherence was facilitated by attitudes and views (about COVID-19 and the importance or protective behaviours), satisfaction with the level of social contact, and practical issues (the ease of the saliva test, the efficiency of the testing service and the convenience of testing within accommodation).

Testing adherence was hindered by changes in procedures or logistics, such as timings for sample drop-off, and inconsistency in messages around rules and regulations delivered by different staff groups and student representatives. One barrier to intervention success was complacent attitudes and non-compliance with the rules in a minority, which was challenging for staff and frustrating for adhering students. Complacent attitudes and misbehaviour of some students caused frustration among those conforming to the rules. Non-compliance with behavioural regulations (e.g., face coverings, social distancing) was largely due to misunderstanding (of students and some staff groups) what was allowed and where, and frequent changes or inconsistency in messaging, largely brought about by the rapidly changing external context of the pandemic. Studies of health messaging during previous pandemics (e.g., Seale et al, 2011: H1N1) have identified the challenges of communicating effectively to staff and students about the spread of viruses without inciting unnecessary fear or promoting complacency. Further, communications need to account for known variability in health literacy in student populations (Chesser et al, 2020), and empathy in messaging is critical but often overlooked in a pandemic situation (Slagle et al, 2021).

The prevalence of mental health concerns among students at this point in the pandemic should not be underestimated. Our qualitative findings highlight the widespread belief that relaxed social distancing within the residence was beneficial for students' mental well-being; some students viewed this social contact as essential for their mental health. Nevertheless, in our survey, all students reported signs of anxiety and almost half our sample (46\%) had clinically relevant anxiety levels (moderate to severe score on the GAD-7). The negative impact of the COVID-19 pandemic on university students' mental well-being is already established (refs), is associated with increased social isolation (Hamza et al, 2021) and is likely to have long-term consequences on students' health and education (Browning et al, 2021). This highlights the importance of initiatives that create opportunities for safe social contact during the pandemic. Social interaction was deemed to be exceptionally important for mental health by this student group and there was an overwhelming perception that the benefits of social interaction to mental health outweighed the risk of virus transmission, which they perceived to be low. Therefore, efforts to engage students in COVID-19 mitigation initiatives that provide socialising opportunities and a perceived return to a more 'normal university experience' may be more successful than those focusing on testing uptake alone.

Our results will help to inform whether, and how, asymptomatic testing could be implemented in residences at other campus-based university settings as part of COVID-19 outbreak prevention and management approaches in higher education environments. Although the intervention was shorter than planned, findings support the premise that that residence-based high-frequency repeated testing may be an effective strategy for COVID-19 mitigation. The RB-TPP approach was perceived by students and staff to be acceptable, increased perceptions of safety on campus and assisted 
in normalisation of university life with benefits for mental well-being during an extended pandemic. This process evaluation supports the implementation of such schemes, but future success relies on the necessary infrastructure or funding for implementation, expectation checks with students, and consistency of messaging relating to changes in processes and behavioural expectations. Key findings and recommendations are shown in Figure 2.

\section{Study limitations}

Log file analysis for identification of multiple survey entries was not used; Internet Protocol (IP) addresses were not available. The survey response rate was low, although respondents were broadly representative of the wider pool of students registered as living at the two participating sites. The views of non-participants in the programme were invited but are under-represented.

\section{Reflection on rapid process evaluation approaches}

The process evaluation was designed in alignment with a pre-determined logic model, which assumes linear and predictive pathways. However, our findings demonstrate that even over a 4-week period, participants (students, service providers) may adapt (intentionally or unintentionally) as they respond to feedback (e.g., from university students or staff, and local public health teams) and contextual changes (e.g., escalation of the Delta variant, changes in national guidelines). The context of rapidly changing global circumstances required immediate responsiveness in local outbreak prevention and management approaches. Our study went beyond adherence or non-adherence to the implementation plan and recognised the reasons for in-situ changes as they occurred, allowing for process evaluation to feedback into the operationalisation of the service. As such, for a process evaluation conducted alongside the implementation of an intervention within a complex organisational system, in the context of a pandemic we would advocate for a more developmental approach requiring an emergent perspective (Patton, 2010; Brennon, 2013).

\section{Conclusions}

To our knowledge, this study is the first process evaluation conducted alongside a university residence-based asymptomatic SARS-CoV-2 testing intervention during the global COVID-19 pandemic. The RB-TPP intervention for students in university residences increased testing behaviour and improved students' mental wellbeing. It was adequately delivered, well-received and could be implemented more widely with some modifications to optimise future delivery.

\section{Abbreviations}

ATS Asymptomatic Testing Service

COM-B Capability, Opportunity, Motivation - Behaviour

PCR Polymerase Chain Reaction

PPIE Patient and Public Involvement and Engagement

RB-TPP Residence-Based Testing Participation Pilot

SARS-CoV-2 SARS Coronavirus 2

UK United Kingdom

\section{Declarations}


The study was carried out in accordance with the Helsinki Declaration. The process evaluation ran alongside an asymptomatic SARS-CoV-2 testing service (Service Registration: UKAS 307727-02-01). The process evaluation is registered on ClinicalTrials.gov (Identifier: NCT05045989). Ethical approval was granted by University of Nottingham

Medical School Research Ethics Committee (Ref: FMHS 96-0920 amendment no 6: 26.04.2021, approved on $4^{\text {th }}$ May 2021, title: 'Extended longitudinal study of SARS-Coronavirus type 2 infection in university staff and students through enhanced SARS2 coronavirus testing and follow-up'). Informed consent was obtained from all participants in the RB-TPP. Service providers and service users received written information and provided online consent for interview; assumed consent was taken for completion of the survey. Participant interviews were transcribed and de-identified. All participants were assigned an identifier for anonymity and reporting purposes. All data was kept confidential.

\section{Consent for publication Not applicable.}

Availability of data and materials The datasets used and/or analysed during the current study are available from the corresponding author on reasonable request.

Competing interests CD is Academic Lead and cofounder of the University of Nottingham Asymptomatic Testing Service (UoN ATS). AF and JB are cofounders of UoN ATS. JC sits of the University of Nottingham Executive Board. None were involved in process evaluation data collection or analysis. HB is a behavioural advisor for the ATS; JB is ATS virology advisor. Neither were involved in service delivery. SC, LF, JH reported no potential conflicts of interests.

Funding This study was supported by the Medical Research Council COVID-19 Urgency Award (COVID-19 in university settings), grant number MC_PC_20027. The funding body was not involved in the design of the study, collection, analysis, and interpretation of data, or writing the manuscript.

Authors' contributions $\mathrm{HB}, \mathrm{AF}$ and JC conceived of the study. $\mathrm{CD}, \mathrm{AF}$ and JB conceived of the intervention. HB designed and oversaw the process evaluation. SC and LF collected and analysed process evaluation data. JH undertook the statistical analysis. CD oversaw the intervention delivery. HB led the write-up of the manuscript with SC and JH. All authors commented on the manuscript and agreed to the final version.

Acknowledgements We thank all participants in the intervention and process evaluation. The RB-TPP was developed by the University of Nottingham in collaboration with the UK Department for Education (in particular, Sophie Westlake), Behavioural Insights Team and Local Public Health/ Public Health England partners in Nottingham and Nottinghamshire. The COVID-19 Testing Operations Group (also Kavita Vedhara, behavioural advisor) and wider UoN ATS team are thanked for delivery of the intervention. Moira Petrie and Amy Stroud are thanked for facilitating recruitment, and also Peter Stephenson for assisting with access to service monitoring data.

\section{References}

Arnold MK, DeFrank G, Arden M, Lee J. Student Ambassador Program to Increase HPV Vaccination Coverage Rates among Adolescents in an East Harlem High School. Pediatrics. 2020:146 (1 Meeting Abstract):48-49; doi:10.1542/peds.146.1_MeetingAbstract.48-a

Barrios LC, Green RF, Honein MA. The role of testing in reducing SARS-CoV-2 transmission on college campuses. Journal of Adolescent Health. 2021;68(1):1-2.

Berger Gillam T, Chin J, Cossey S, Culley K, Davidson RK, Edwards DR, Gharbi K, Goodwin N, Hall N, Hitchcock M, Jupp OJ, Lipscombe J, Parr G, Shearer N, Smith R, Steel N. Phase 2 of the Norwich COVID-19 testing initiative: an evaluation. Journal of Public Health. 2021; doi: 10.1093/pubmed/fdab124. 
Blake H, Corner J, Cirelli C, Hassard J, Briggs L, Daly JM, Bennett M, Chappell JG, Fairclough L, McClure CP, Tarr A, Tighe P, Favier A, Irving W, Ball J. Perceptions and Experiences of the University of Nottingham Pilot SARS-CoV-2 Asymptomatic Testing Service: A Mixed-Methods Study. Int. J. Environ. Res. Public Health 2020;18(1):188; doi:10.3390/ijerph18010188.

Blake H, Knight H, Jia R, Corner J, Morling JR, Denning C, Ball JK, Bolton K, Figueredo G, Morris DE, Tighe P, Villalon AM, Ayling K, Vedhara K. Students' Views towards Sars-Cov-2 Mass Asymptomatic Testing, Social Distancing and SelfIsolation in a University Setting during the COVID-19 Pandemic: A Qualitative Study. Int. J. Environ. Res. Public Health 2021;18(8):4182; doi:10.3390/ijerph18084182.

Braun V, Clarke V. Using thematic analysis in psychology. Qual Res Psychol. 2006;3(2):77-101.

Brennan K. Developmental Evaluation: An Approach to Evaluating Complex Social Change Initiatives. Presentation at Next Generation Evaluation Conference: Embracing Complexity, Connectivity and Change. Stanford University: FSG: Foundation Strategy Group; 2013. http://www.fsg.org/nextgenerationevaluation.aspx.

Browning MHEM, Larson LR, Sharaievska I, Rigolon A, McAnirlin O, Mullenbach L, Cloutier S, Vu TM, Thomsen J, Reigner N, Metcalf EC. Psychological impacts from COVID-19 among university students: Risk factors across seven states in the United States. PLoS ONE. 2021;16(1):e0245327; doi:10.1371/journal.pone.0245327.

Carroll C, Patterson M, Wood S, Booth A, Rick J, Balain S. A conceptual framework for implementation fidelity. Implement Sci. 2007;2(40); doi:4010.1186/1748-5908-2-40.

Cerise FP, Moran B, Bhavan K. Delivering Covid-19 Vaccines by Building Community Trust. NEJM Catalyst, Innovations in Care Delivery. 2021. https://catalyst.nejm.org/doi/full/10.1056/CAT.20.0692

Chesser A, Ham AD, Woods NK. Assessment of COVID-19 Knowledge Among University Students: Implications for Future Risk Communication Strategies. Health Education and Behavior, 2020;47;4: 540-543.

Covid-19 Case Dashboard: Monitoring Cases of Covid-19 in UK Higher and Further Education. https://www.ucu.org.uk/covid-dashboard. Accessed 15 Nov 2020.

Creswell JW, Clark VLP. Designing and conducting mixed methods research: Wiley online library; 2007.

Davies NG, Klepac P, Liu Y, Prem K, Jit M, Eggo RM. Age-dependent effects in the transmission and control of COVID-19 epidemics. Nature medicine. 2020;26(8):1205-11.

Department of Health and Social Care. NHS Test and Trace: what to do if you are contacted. 27 May 2020. Last updated 17 Aug 2021. https://www.gov.uk/guidance/nhs-test-and-trace-how-it-works. Accessed 20 Aug 2021.

Ebell MH, Chupp C, Bentivegna M. A high proportion of SARS-CoV-2-infected university students are asymptomatic. J Fam Pract, 2020;69(9):428-429.

Hamza CA, Ewing L, Heath NL, Goldstein AL. When social isolation is nothing new: A longitudinal study on psychological distress during COVID-19 among university students with and without preexisting mental health concerns. Canadian Psychology/Psychologie canadienne. 2021;62(1):20.-30; doi:10.1037/cap0000255.

Hoffmann T, Glasziou P, Boutron I, Milne R, Perera R, Moher D, Altman D, Barbour V, Macdonald H, Johnston M, Lamb S, Dixon-Woods M, McCulloch P, Wyatt J, Chan A, Michie S. Better reporting of interventions: template for intervention description and replication (TIDieR) checklist and guide. BMJ. 2014;348:g1687. 
India Today. $90 \%$ of world's population still susceptible to coronavirus: WHO chief scientist. $28^{\text {th }}$ September 2020. https://www.indiatoday.in/programme/news-unlocked-with-rajdeep-sardesai/video/90-per-cent-world-populationstill-susceptible-coronavirus-who-chief-scientist-1726384-2020-09-28. Accessed 20 Aug 2021.

Kroenke K, Spitzer RL, Williams JB, Monahan PO, Löwe B. Anxiety disorders in primary care: prevalence, impairment, comorbidity, and detection. Annals of internal medicine. 2007;146(5):317-25.

Lanou AJ, Perry J, Perry LG, Garland B, Hunt K, Gold-Leighton K. Practice Report: Student Health Ambassadors at Residential Campuses Contribute to Safer Campus Living and Learning During the COVID-19 Pandemic. Journal of Higher Education Theory and Practice, 2021;21(8).

Long A, Mathew S, Alvarez KS, Smartt JS, Shah M, Madden C, Perl TM, Cerise FP, Bhavan KP. Co-Created Messaging for Influenza Vaccination in a High-Risk Hispanic Community Provides Groundwork for COVID-19 Vaccine. Health Equity. 2021;5(1):345-352; doi:10.1089/heq.2020.0132.

Michie S, Van Stralen MM, West R. The behaviour change wheel: a new method for characterising and designing behaviour change interventions. Implement Sci. 2011;6(1):42.

Moore GF, Audrey S, Barker M, Bond L, Bonell C, Hardeman W, Moore L, O'Cathain A, Tinati T, Wight D, Baird J. Process evaluation of complex interventions: Medical Research Council guidance. bmj. 2015;19;350.

Nacher M, Mergeay-Fabre M, Blanchet D, Benoit O, Pozl T, Mesphoule P, Sainte-Rose V, Vialette V, Toulet B, Moua A, Saout M, Simon S, Guidarelli M, Galindo M, Biche B, Faurous W, Chaizemartin L, Fahrasmane A, Rochemont D, Vignier N, Vabret A, Demar M. Prospective Comparison of Saliva and Nasopharyngeal Swab Sampling for Mass Screening for COVID-19. Front Med (Lausanne), 2021;8:621160; doi:10.3389/fmed.2021.621160.

O’Donnell C, Brownlee K, Martin E, Suyama J, Albert S, Anderson S, Bhatte S, Bonner K, Burton C, Corn M, Eng H, Flage B, Frerotte J, Balasubramani GK, Haggerty C, Haight J, Harrison LH, Hartman A, Hitter T, King WC, Ledger K, Marsh JW, McDonald MC, Miga B, Moses K, Newman A, Ringler M, Roberts M, Sax T, Shekhar A, Sterne M, Tenney T, Vanek M, Wells A, Wenzel S, Williams J. SARS-CoV-2 Control on a Large Urban College Campus Without Mass Testing. medRXiv Pre-print, 2021; doi:10.1101/2021.01.21.21249825.

Packel P, Reingold A, Hunter L, Facente S, Li Y, Harte A, Nicolette G, Urnov FD, Lu M, Petersen M, IGI Testing Consortium. Piloting an integrated SARS-CoV-2 testing and data system for outbreak containment among college students: A prospective cohort study. PLoS One. 2021;16(1):e0245765.

Patton MQ. Developmental evaluation: applying complexity concepts to enhance innovation and use. New York: Guilford Press; 2010.

QSR International Pty Ltd. (2020) NVivo (released in March 2020), https://www.qsrinternational.com/nvivo-qualitativedata-analysis-software/home

Rennert L, McMahan C, Kalbaugh CA, Yang Y, Lumsden B, Dean D, Pekarek L, Colenda CC.

Surveillance-based informative testing for detection and containment of SARS-CoV-2 outbreaks on a public university campus: an observational and modelling study. The Lancet Child \& Adolescent Health. 2021;5(6):428-436.

Seale H, McLaws M, Van D, Crimmins J, Maclntyre CR. University Communication Strategies During a Pandemic-Were the Messages Received?. Journal of Public Health Management and Practice, 2011;17(1):E29-E32; doi:10.1097/PHH.0b013e3181d3cb8e.

Page 27/31 
Slagle DR, Mclntyre JJ, Chatham-Carpenter A, Reed HA. The perfect storm in the midst of a pandemic: the use of information within an institution's concurrent crises. Online Information Review. 2021;45(4);656-671; doi:10.1108/0IR-092020-0415.

Spitzer RL, Kroenke K, Williams JB, Löwe B. A brief measure for assessing generalized anxiety disorder: the GAD-7. Archives of internal medicine. 2002;166(10):1092-7.

Tong A, Sainsbury P, Craig J. Consolidated criteria for reporting qualitative research (COREQ): a 32-item checklist for interviews and focus groups. International journal for quality in health care. 2007;19(6):349-57.

Tsang NNY, So HC, Ng HY, Cowling BJ, Leung GM, Ip DKM. Diagnostic performance of different sampling approaches for SARS-CoV-2 RT-PCR testing: a systematic review and meta-analysis. Lancet Infect Dis. 2021;21(9):1233-1245; doi:10.1016/S1473-3099(21)00146-8.

Twohig KA, Nyberg T, Zaidi A, Thelwall S, Sinnathamby MA, Aliabadi S, Seaman SR, Harris RJ, Hope R, Lopez-Bernal J, Gallagher E, Charlett A, De Angelis D, Presanis AM, Dabrera G, the COVID-19 Genomics UK (COG-UK) consortium. Hospital admission and emergency care attendance risk for SARS-CoV-2 delta (B.1.617.2) compared with alpha (B.1.1.7) variants of concern: a cohort study. The Lancet: Infectious Diseases. 2021; doi:10.1016/S1473-3099(21)00475-8.

Vermund SH, Pitzer VE. Asymptomatic Transmission and the Infection Fatality Risk for COVID-19: Implications for School Reopening. Clin Infect Dis. 2021;72(9):1493-1496.

Walke HT, Honein MA, Redfield RR. Preventing and responding to COVID-19 on college campuses.

Jama. 2020;324(17):1727-8.

World Health Organization. Transmission of SARS-CoV-2: implications for infection prevention precautions. Scientific Brief, 9 July 2020. https://www.who.int/news-room/commentaries/detail/transmission-of-sars-cov-2-implications-for-infectionprevention-precautions. Accessed 20 Aug 2021.

Yanes-Lane M, Winters N, Fregonese F, Bastos M, Perlman-Arrow S, Campbell JR, Menzies D. Proportion of asymptomatic infection among COVID-19 positive persons and their transmission potential: A systematic review and meta-analysis. PloS one. 2020;15(11):e0241536.

Zhao M, Seals B, Elliott K, Kartoz C, King R, Patterson N, Brown N, Vermeychuk J, Kuiphoff J, Gladysiewicz R, Souza M, Gorman M, Lazzaro L, Zambrano H, Ferrara E, Doughan E, Patel A. Knowledge Matters: Evaluating a College Flu Vaccination Campaign. APHA's 2019 Annual Meeting and Expo (Nov. 2 - Nov.

6). https://apha.confex.com/apha/2019/meetingapi.cgi/Paper/449398?

filename=2019_Abstract449398.html\&template=Word

Zimba R, Kulkarni S, Berry A, You W, Mirzayi C, Westmoreland D, Parcesepe A, Waldron L, Rane M, Kochhar S, Robertson M, Maroko A, Grov C, Nash D. SARS-CoV-2 Testing Service Preferences of Adults in the United States: Discrete Choice Experiment. JMIR Public Health Surveill, 2020; 6(4):e25546; doi:10.2196/25546.

\section{Figures}




\begin{tabular}{|c|c|c|c|c|c|}
\hline \multirow{2}{*}{\begin{tabular}{l}
\multicolumn{1}{c}{ Inputs } \\
University Asymptomatic \\
Testing Service \\
Testing staff, laboratories and \\
funding for delivery of PCR \\
saliva testing for SARS-CoV- \\
2.
\end{tabular}} & \multicolumn{2}{|c|}{ Outputs } & \multicolumn{3}{|c|}{ Outcomes - Impact } \\
\hline & Activities & Participation & Immediate results & Intermediate outcomes & Long-term outcomes \\
\hline $\begin{array}{l}\text { University Asymptomatic } \\
\text { Testing Service } \\
\text { Testing staff, laboratories and } \\
\text { funding for delivery of PCR } \\
\text { saliva testing for SARS-CoV- } \\
2 . \\
\text { Oversight \& Governance } \\
\text { Project Group review } \\
\text { progress weekly. Public } \\
\text { Health oversight provided by } \\
\text { Local Public Health Teams \& } \\
\text { Public Health England East } \\
\text { Midlands Health Protection } \\
\text { Team.Policy oversight } \\
\text { provided by UK Department } \\
\text { for Education. Operational } \\
\text { ownership, funding and } \\
\text { delivery provided by host } \\
\text { University. Academic input } \\
\text { provided by experts group } \\
\text { including Virologist, } \\
\text { Infectious Diseases Modeller, } \\
\text { Cell Biologist, Behavioural } \\
\text { Psychologist. Mixed-methods } \\
\text { process evaluation } \\
\text { undertaken by independent } \\
\text { research team. Support for } \\
\text { evaluation and assessment } \\
\text { provided by UK Government } \\
\text { Behavioural Insights Team. } \\
\text { Risk Assessment } \\
\text { Host University undertook a } \\
\text { legal, financial and health and } \\
\text { safety risk assessment of the } \\
\text { scheme. The scheme was also } \\
\text { reviewed by the University's } \\
\text { Ethics Committee. }\end{array}$ & $\begin{array}{l}\text { SARS-CoV-2 Testing } \\
\text { Resident students take SARS- } \\
\text { CoV-2 saliva tests, twice per } \\
\text { week, over } 4 \text { weeks. Tests } \\
\text { provided more than } 2 \text { days } \\
\text { apart in accordance with } \\
\text { DHSC guidance. Students } \\
\text { who have been a contact of a } \\
\text { positive case take tests for } 7 \\
\text { days as an alternative to self- } \\
\text { isolation. For outbreak } \\
\text { control assurance, whole } \\
\text { residence surge testing is } \\
\text { undertaken after } \\
\text { identification of a positive } \\
\text { case. } \\
\text { Social Behaviour } \\
\text { Social interaction is allowed } \\
\text { between members of } \\
\text { residence (only within the } \\
\text { residence). Face coverings } \\
\text { must be worn within the } \\
\text { residence in communal areas. } \\
\text { Students must maintain } \\
\text { social distancing ( } 2 \text { metres) } \\
\text { when interacting with staff. } \\
\text { All other rules governing } \\
\text { social interaction should } \\
\text { apply inside and outside of } \\
\text { the hall. } \\
\text { Contact Tracing } \\
\text { Delivered locally rather than } \\
\text { nationally. } \\
\text { Support for Self-isolation } \\
\text { and Positive Cases } \\
\text { Positive cases provided with } \\
\text { alternative accommodation. } \\
\text { Welfare support and peer } \\
\text { support provided by the } \\
\text { University's pastoral teams. }\end{array}$ & $\begin{array}{l}\text { Implementation fidelity: } \\
\text { Reach: Target is } 90 \% \text { of } \\
\text { resident students consenting } \\
\text { to take part. } \\
\text { Testing Engagement: defined } \\
\text { as taking } 1 \text { SARS-CoV-2 test } \\
\text { during the programme. } \\
\text { Testing Compliance: defined } \\
\text { as taking } 2 \text { tests per week. } \\
\text { Barriers and facilitators: } \\
\text { Interviews with residence-based } \\
\text { testing champions } \\
\text { To facilitate testing } \\
\text { engagement and support } \\
\text { messaging related to testing } \\
\text { and social behaviour. } \\
\text { Post-survey with students } \\
\text { Interviews with students } \\
\text { Interviews with staff }\end{array}$ & $\begin{array}{l}\text { Up to } 90 \% \text { of residents will } \\
\text { opt to participate (reach). } \\
\text { Determine reasons for } \\
\text { participation and non- } \\
\text { participation in residence- } \\
\text { based testing. } \\
\text { Over } 80 \% \text { of participants will } \\
\text { complete at least one test } \\
\text { (engagement). } \\
\text { Over } 50 \% \text { of participants will } \\
\text { be fully compliant with } \\
\text { testing twice per week } \\
\text { (compliance). } \\
\text { Determine facilitators of } \\
\text { testing and correlates of } \\
\text { testing frequency. } \\
\text { Programme delivered twice } \\
\text { weekly testing for } 4 \text { weeks } \\
\text { (dose and timeliness) } \\
\text { Adherence to social } \\
\text { expectations: social } \\
\text { distancing, self-isolation, and } \\
\text { face coverings. } \\
\text { Determine acceptability to } \\
\text { students and staff of: } \\
\text { Residence-based testing, local } \\
\text { contact tracing, surge testing, } \\
\text { social expectations. }\end{array}$ & $\begin{array}{l}\text { Number of cases of COVID- } \\
19 \text { identified within the } \\
\text { residences. } \\
\text { Student and staff perceptions } \\
\text { of safety on campus. } \\
\text { Wellbeing of students. } \\
\text { Forward planning for } \\
\text { continuation / extension of } \\
\text { the RB-TPP. }\end{array}$ & $\begin{array}{l}\text { Residence-based } \\
\text { asymptomatic testing for } \\
\text { SARS-CoV-2 in university } \\
\text { students will be adopted as } \\
\text { one approach to reduce the } \\
\text { risk of outbreaks of COVID } \\
19 \text { and increase perceptions } \\
\text { of safety on campus. }\end{array}$ \\
\hline \multicolumn{3}{|c|}{$\begin{array}{l}\text { Goal Statement } \\
\text { Residence-based asymptomatic testing for SARS-CoV-2 in university students will reduce the } \\
\text { risk of outbreaks of COVID-19 and increase perceptions of safety on campus. } \\
\text { Theory of Change } \\
\text { Providing students with access to twice-weekly asymptomatic PCR testing for SARS-CoV-2 } \\
\text { within their place of residence will lead to high uptake of PCR testing. This in turn will reduce } \\
\text { risk of COVID-19 outbreak in the residences and increase perceptions of safety on campus. } \\
\text { Concurrent relaxation of student-to-student social distancing regulations will enhance student } \\
\text { wellbeing, which in turn will maximise testing behaviour. } \\
\text { Assumptions } \\
\text { A successful programme will be: highly accessed (wide reach), timely, of sufficient dose, } \\
\text { acceptable to staff and students. }\end{array}$} & \multicolumn{3}{|c|}{$\begin{array}{l}\text { External Factors } \\
\text { Availability of asymptomatic tests. } \\
\text { Ourcome of legal, financial, health \& sfaty risk assessments. } \\
\text { Changes in local or national COVID-19 case rates. } \\
\text { Changes in government regulations relating to COVID-19. }\end{array}$} \\
\hline
\end{tabular}

\section{Figure 1}

\section{Logic Model for Residence-Based SARS-CoV-2 Testing Participation Pilot}


Key findings

- Offering COVID-19 tests in university residences is viewed positively, with broad uptake and reach.

- Testing engagement is high ( $88 \%)$, compliance with twice-weekly testing is lower (46\%).

- The concept of surge testing is seen to be an acceptable outbreak mitigation strategy.

- Regularly testing contacts of positive cases is perceived to be preferable to self-isolation.

- The concept of surge testing is seen to be an acceptable outbreak mitigation strategy.

- Relaxed social restrictions improve student satisfaction and mental health.

- Most students are compliant with residence-based COVID-19 social regulations but those who are not create challenges and stressors for peers and staff.

- Responding to the changing landscape of a pandemic is challenging for staff.

Key recommendations to maximise uptake, adherence and compliance

- Written communications for students should be briefer, empathetic, positive and persuasive but avoid punitive tone.

- Students require clear and specific rules outlining expectations around social distancing, mask wearing and socialising, with explanations for changes.

- Communications should be delivered consistently across all staff groups to avoid mixed messages.

- Timings for kit collection and sample drop-off need to be accessible around meals and academic commitments.

- Involving students in programme planning is essential to ensure procedures and communications match the needs of the student population.

- Involving staff with student-facing roles in programme planning is essential to establish clear lines of communication and to ensure procedures are practical and achievable.

- Student ambassadors are a useful mechanism for provision of peer-to-peer support and assistance with communications.

- Regular updates on testing uptake rates are valued by and motivate students.

- Incentives to participate need to be well promoted and will likely be more effective if aligned with what is valued by students (e.g., socialising opportunities).

- Normalising residence-based testing will be important for future uptake.

Figure 2

Key findings and recommendations

\section{Supplementary Files}

This is a list of supplementary files associated with this preprint. Click to download.

- Additionalfile1Explanationofterms.pdf

- Additionalfile2COREQ32.pdf

- Additionalfile3TiDieRChecklist.pdf

- Additionalfile4Programmeendsurvey.pdf

- Additionalfile5Questionguides.pdf 
- Additionalfile6StudenthealthandexposuretoCOVID19.pdf

Page 31/31 